\title{
"Serás estropiado, maltratado e triturado na Amazônia": trabalhadores cearenses na Campanha Nacional da Borracha, zona noroeste do Ceará $(1942-1945)^{*}$
}

\author{
"The Amazon will crush you, mistreat and leave you foul": \\ Workers from the northeast of Ceara, Brazil, in the Rubber National \\ Campaign (1942- 1945)
}

\section{Carlos Augusto Pereira dos Santos**}

\begin{abstract}
Resumo: Apesar de os trabalhadores chamados de "Soldados da borracha" não terem participado propriamente das grandes construções de modernização econômica global, posto que atuaram no contexto da Segunda Guerra Mundial trabalhando nos seringais da Amazônia numa atividade quase que exclusivamente extrativa, merece atenção da análise histórica o processo de recrutamento, treinamento e as condições de vida e trabalho a que esses trabalhadores estiveram sujeitos durante a Campanha Nacional da Borracha, feito pelo Serviço Especial de Mobilização de Trabalhadores para a Amazônia - SEMTA. Longe de casa, milhares de nordestinos seguiram para os seringais do norte do Brasil, buscando fugir da seca e do front da guerra, aliciados com promessas de ganho e riquezas. Este artigo procura evidenciar as trajetórias de vida desses homens, especialmente da região noroeste do estado do Ceará, ainda pouco mencionados na historiografia cearense, numa perspectiva da história social.
\end{abstract}

Palavras-chave: Trabalhadores; SEMTA; soldados da borracha.

Expressão transformada pelos "arigós", como eram chamados os trabalhadores nordestinos enviados para os seringais da Amazônia, a partir da sigla do SEMTA - Serviço de Especial de Mobilização de Trabalhadores para a Amazônia, órgão do governo federal responsável pelo envio dos mesmos. De alguma forma, isto revela a capacidade do sertanejo, especialmente o cearense, em fazer troça do seu próprio infortúnio.

** Professor do Curso de História da Universidade Estadual Vale do Acaraú - UVA. ORCID: https://orcid.org/00000002-1734-9677. E-mail: augustus474@hotmail.com. 
Abstract: The working conditions and most of all the way of recruiting the "rubber soldiers" in the National Rubber Campaign happened with the Special Service for the Mobilization of Workers for the Amazon (SEMTA) needs to be historically analyzed and carefully understood although it is not part of an impacting economic deal of the Second World War period, and did not bring development to the Amazon once this was an exclusively extractive activity. Thousands of male northeastern workers were allured to the rubber plantations fleeing from the devastating dry seasons, recruitment to war and starvation with the promise of riches and wealth. Through the narratives of the life stories of these men we will try to bring light upon one of the ignored pages of social history of the northeastern workers from the north of Ceará, Brazil.

Keywords: Workers; SEMTA; "Rubber Soldiers".

\section{Introdução}

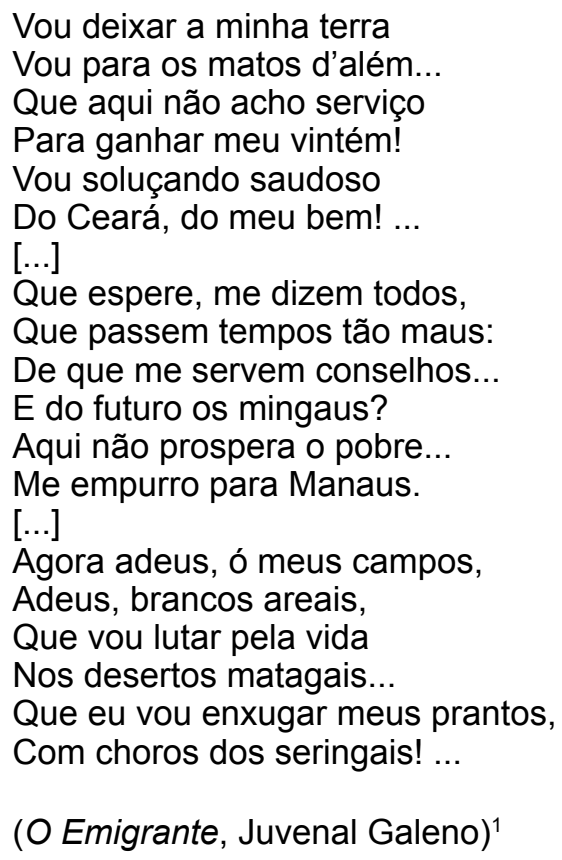

$\mathbf{N}_{\text {nom }}$ FINAL DO SÉCULO XIX, quando das secas de 1877-1879 e de 1888-1889, a população nordestina foi "socorrida", não sem muita polêmica, com passagens para os portos do norte e do sul do país. Com efeito, desde a segunda metade do século XIX que esse expediente era usado pelo governo imperial, além das chamadas "obras de socorro público". No entanto, para este trabalho, enfocaremos os fatos e discussões sobre a questão da emigração, notadamente para a Amazônia em seu segundo movimento mais significativo: entre 1942 a 1945, por conta da conjuntura da Segunda Guerra Mundial e dos esforços brasileiros para o que se convencionou chamar de "Batalha da Borracha". ${ }^{2}$

1 GALENO, Juvenal. Lendas e canções populares. $5^{a}$ ed. Fortaleza: Secult, 2010. p. 528-531.

2 Para um maior aprofundamento dessa questão, cf.: SECRETO, Maria Verónica. Ceará, a fábrica de 
"Serás estropiado, maltratado e triturado na Amazônia":

Por outro lado, espacialmente falando, nossa intenção é de lançar luzes sobre essa conjuntura que alterou o mundo do trabalho na região noroeste do estado do Ceará e a sua estrutura no que diz respeito à logística de envio de trabalhadores da região para o Norte através do porto de Camocim e dos "pousos" de Sobral e Tianguá. Apesar de referenciados pela historiografia do tema, a menção da zona noroeste do estado como receptora de retirantes (para o litoral de Camocim e Acaraú) e exportadora de trabalhadores (através do porto de Camocim e os "pousos" de Sobral e Tianguá) para a Amazônia é tão "passageira" quanto o tempo de recrutamento e preparação dos mesmos para a viagem aos "matos d'além", como metaforizou a região amazônica o poeta Juvenal Galeno.

De algum modo, a relevância dada pela historiografia aos retirantes nos campos de concentração localizados na periferia da cidade de Fortaleza, ou ao seu cotidiano na Hospedaria Getúlio Vargas na capital cearense, passa-nos uma ideia de que o processo de recrutamento tenha se dado quase prioritariamente nestes lugares. Por sua importância, tamanho e localização, uma exceção no estudo destes campos se dá com relação ao campo de concentração do município de Ipu durante a seca de 1932, funcionando como espécie de contenção de flagelados na então região norte do Ceará, que poderiam buscar outros centros, como Fortaleza. ${ }^{3}$ Contudo, entendemos que, para além dessa preferência historiográfica, talvez o mais importante sejam os sentidos e significados da política governamental de assistência aos flagelados das secas e o seu controle social, como bem expressa o historiador Frederico de Castro Neves:

Assim, um amplo programa de criação de campos de concentração, em que os retirantes fossem induzidos a entrar e proibidos de sair, foi implementado com total apoio da Interventoria Federal no Ceará. A fim de prevenir a "afluência tumultuária" de retirantes famintos a Fortaleza, cinco campos localizavam-se nas proximidades das principais vias de acesso à capital, atraindo os agricultores que perdiam suas colheitas e se viam à mercê da caridade pública ou privada. Dois campos menores situavam-se em locais estratégicos de Fortaleza, conectados às estações de trem que traziam os famintos, impedindo que eles circulassem livremente pelos espaços da capital. Uma vez dentro do campo, o retirante era obrigado não só a permanecer nele durante todo o período considerado de seca, mas deveria submeter-se a condições de moradia, relacionamento, trabalho e comportamento regulados pelas normas irredutíveis ditadas pelos dirigentes indicados pelo interventor - prefeitos nomeados e engenheiros do IFOCS. Os campos, portanto, pretendiam impedir a mobilidade física e política dos retirantes através da concessão de rações diárias e de assistência médica. ${ }^{4}$

trabalhadores: emigração subsidiada no final do século XIX. Trajetos. Revista de História UFC. Fortaleza, v. 2 , n. 4, 2003; SOUZA, José Weyne Freitas. Secas e socorros públicos no Ceará. Doença, pobreza e violências. (1877-1932). Projeto História. São Paulo, n. 52, p. 178-219, jan.-abr. 2015; FERREIRA, Lara Vanessa de Castro. Políticas antimigratórias e circulação de "retirante": tessituras entre trabalho e migração nas obras públicas em tempos de secas no Ceará (década de 1950). Cadernos de História, Belo Horizonte, v. 16, n. 25, $2^{\circ}$ sem. 2015.

3 Com relação ao campo de concentração do Ipu, ver, principalmente: ARAÚJO, Raimundo Alves de; SILVEIRA, Edvanir Maia da. A cidade e seca: o campo de concentração de 1932 e as transformações urbanas em Ipu-CE. Revista da Casa da Geografia, Sobral, v. 8, n. 1, 2006; SANTOS, Maria Janicleia dos. Poder e trabalho no campo de concentração de Ipu. Revista Historiar, Sobral, v. 6, n. 10, 2014; RIOS, Kênia Sousa. Campos de concentração no Ceará: isolamento e poder na seca de 1932. Coleção Outras Histórias. Fortaleza: Museu do Ceará/Secretaria da Cultura do Estado do Ceará, 2001.

4 NEVES, Frederico de Castro. Getúlio e a seca: políticas emergenciais na era Vargas. Revista Brasileira de História. São Paulo, v. 21, n. 40, p. 107-131, 2001. p. 109. 
O modo de se receber os famintos da seca na capital alencarina faz-nos pensar se o mesmo não se configurava com os demais lugares de "concentração" de retirantes, como os pousos de Sobral e Tianguá. Embora não tendo a mesma característica de controle social dos campos de concentração, no sentido de diminuir o contato dos retirantes com a população fortalezense, notadamente com setores da elite, o fato dos pousos se localizarem na periferia dessas cidades denuncia alguma relação de controle. Seja no bairro da Cruz das Almas em Sobral ou nas margens da BR-222 em Tianguá, os pousos dos futuros soldados da borracha eram espaços, senão estigmatizados, um pouco longe dos olhos da urbe.

Voltando para os fatores que ensejaram a emigração nos períodos acima demarcados, percebe-se que a mesma não era um ponto pacífico em sua operacionalização, tanto como política governamental quanto para quem emigrava fugindo dos rigores das secas. Posicionamentos prós e contras foram estampados, por exemplo, na imprensa da época, como assinala a historiadora Maria Verónica Secreto:

O modelo de emigração, que incluía as passagens subvencionadas para outras províncias do Império, teve opositores locais. A imprensa, através do jornal $O$ Cearense, fez uma campanha de oposição: primeiro, em 1877-1879, opõe-se à imigração para o Norte e depois, em 1888-1889, opõe-se à imigração para o sul. [...] A emigração foi colocada pelos contemporâneos como solução extrema. Isto não quer dizer que não houvesse setores beneficiando-se com a emigração, como as companhias de navegação, os comerciantes de gêneros de primeira necessidade e os fazendeiros que empregariam estes emigrantes; mas todos afirmavam que esta acontecia em última instância, quando já se tinham esgotado todas as outras alternativas de solucionar o problema dentro do território atingido pela seca. ${ }^{5}$

Duas questões emergem da citação acima. Primeira: embora o debate sobre o destino dos emigrantes se polarizasse entre o norte e o sul, há que se mencionar o movimento interno na província do Ceará, quando se volta o olhar para a documentação produzida pela Inspetoria Geral da Imigração, com relação aos pedidos de subvencionamento de passagens para os mais "diferentes lugares do Império". Embora a grande maioria (96,49\% de um total de 314 pedidos) tivesse como preferência os portos do Norte e do Nordeste), alguns pedidos eram para: "7 para Camocim; 3 para Aracaty; 2 para Acarahú", segundo a autora citada acima, baseada em documentação do Arquivo Público do Estado do Ceará. ${ }^{6}$ Este movimento interno, no entanto, se verificava desde a seca de 1877 , quando milhares de sertanejos se deslocaram, segundo o historiador Tyrone Apollo Pontes Cândido, "em direção aos centros mais férteis, como as serras de Baturité, Araripe, Maranguape e Ibiapaba, o vale do Parnaíba, no Piauí, ou as cidades litorâneas (Camocim, Aracati e, principalmente, Fortaleza)".7

5 SECRETO, op. cit., 2003, p. 56.

6 Ibidem, p. 58. Afirmação fundamentada em documentação do APEC. Inspetoria Geral de Emigração. Relação dos emigrantes Norte-Sul, 1888-1889.

7 CÂNDIDO, Tyrone Apollo Pontes. Trem da seca. Sertanejos, retirantes e operários (1877-1880). Coleção Outras Histórias - 32. Fortaleza: Museu do Ceará/Secretaria da Cultura do Estado do Ceará, 2005. p. 41. 
A segunda questão refere-se ao embarque de trabalhadores para fora da província beneficiando as companhias de navegação. Embora Camocim estivesse longe dos editoriais inflamados que denunciavam o tráfico das "victimas da seca" para os portos do norte e sul do país, por seu porto também se fazia esse tráfico. Com efeito, desde a segunda metade do século XIX que levas de cearenses seguiam para o norte amazônico. Em 1869, "[...] João Gabriel de Carvalho e Melo, um pioneiro paroara, levou 50 homens da serra de Uruburetama para o baixo Purus. No mesmo ano, 1.603 cearenses migraram para o Amazonas". ${ }^{8}$ Antes que o século $X X$ raiasse e o porto de Camocim ganhasse as manchetes dos jornais, com veremos abaixo, o ano de 1900 registrava a intensidade desse trânsito de trabalhadores: "[...] seguiram mais de 15.773 migrantes, dos quais 9.296 embarcados em Fortaleza e 6.477 no porto de Camocim - todos com ajuda e passagem do governo federal. Consolidava-se um fluxo migratório no eixo Nordeste/Amazônia". ${ }^{9}$ No ano seguinte, o assunto foi tema das matérias jornalísticas da imprensa de Sobral, que tiveram repercussão na capital. Vale a pena transcrever a matéria na íntegra para termos ideia de como os jornais expressavam seus posicionamentos sobre a emigração em 1901:

\section{Miséria!}

D' A Cidade, de Sobral, neste Estado, extraímos o seguinte:

\section{EXPATRIAÇÃO}

Por comunicação que tivemos de Camocim sabemos que o Rio, que zarpou d'aquelle porto no dia 13 do corrente, conduziu para os portos do Norte mais 986 vítimas da iniquidade do sr. Presidente da República.

O que há de mais repugnante, asqueroso e imoral vai se representar no bojo do pequenino vaso, que, além d'aquelle avultado número de infelizes, recebeu a carga de 20 burros.

Seja tudo por amor desse governo.

O numero de famintos expelidos do torrão natal pelo porto de Camocim atinge a 3335 e a emigração continua aberta, franca, para todos os Estados da União.

No Camocim está se dando atualmente um movimento de embarque de gente para o Pará e Amazonas como o de bois até bem pouco.

Acabou-se o gado bovino e o Snr. Campos Salles mandou exportar... gado humano.

Pobre Ceará!...

\section{MAIS 1028}

O Jaboatão, que partiu de Camocim no dia 17 do corrente, conduziu para o Norte mais 1028 famintos.

Com esta leva atinge 4456 o número de infelizes que acossados pela fome e abandonados no torrão natal pelo governo da União, têm-se visto forçados a se expatriar para não morrerem de fome.

\footnotetext{
8 FUNES, Eurípedes. Eldorado no Inferno Verde - "Quem vive no inferno se acostuma com os cães". In: GONÇALVES, Adelaide; COSTA, Pedro Eymar (org.). Mais borracha para a vitória. Fortaleza: MAUC/Nudoc; Brasília: Ideal Gráfica, 2008. p. 18.

9 Ibidem, p. 18.
} 
Clamar por quem? Para quem clamar, como pensa Ruy Barbosa?

Chegamos ao extremo do desespero e - Salve-se quem puder.

Pobre Ceará!....10

Como se pode perceber, a solução de mandar trabalhadores em tempos de estiagem para outras paragens, quando do Império, continua na República. Na matéria jornalística acima não há condescendência com o governo e nem resquícios de propaganda oficial, como iria acontecer na conjuntura da Segunda Guerra Mundial. No Império, as políticas de socorros públicos não comportaram a demanda faminta das massas populacionais varridas pela fome e a solução extrema foi enviar trabalhadores para os vazios demográficos do norte e as fazendas do sul. No movimento de mobilização para o esforço de guerra no ano de 1942, o chamariz foi o patriotismo e a promessa de enriquecimento.

Contudo, o espetáculo da emigração no discurso jornalístico no final do século XIX e primeiras décadas do século XX levava a questão para outro extremo: a expatriação. Tomando o texto citado acima, termos como miséria, iniquidade, infelizes, famintos juntam-se à repugnante, asqueroso, imoral compondo quase um grito de desespero dos infelizes "expelidos do torrão natal pelo porto de Camocim". Os famintos, portanto, além dessa condição degradante denunciada pelo jornal, eram transportados como burros, ao lado de burros, fruto da política do presidente da República Campos Salles, que equipara o gado bovino ao gado humano. O Ceará por duas vezes na matéria é alçado à condição de vítima sem ter a quem apelar: Pobre Ceará numa situação de "salve-se quem puder".

Figura 1 - Panorâmica do Cais do Porto de Camocim. Anos 1950.

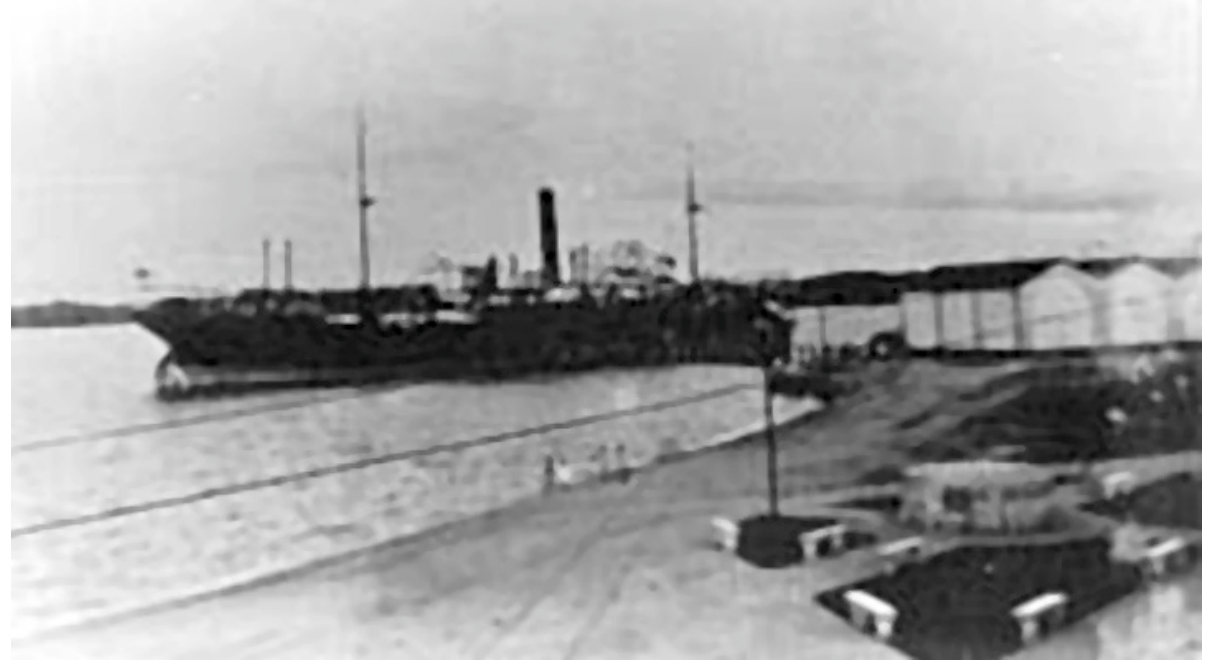

Fonte: arquivo do autor.

10 A Gazetinha, Fortaleza, n. 5, p. 2-3, 11 jan. 1901. Fonte: Hemeroteca da Biblioteca Nacional. 
Os movimentos migratórios de nordestinos que ocorrem desde a segunda metade do século XIX não se deram sem as devidas polêmicas como vimos acima, se constituindo num fenômeno social que perpassa a história do país. Mesmo sendo estigmatizado pela aridez, a fome e a miséria, o estado do Ceará não deixou de ser uma terra "provedora de trabalhadores", como assinala a historiadora Maria Verónica Secreto. Neste momento não iremos aprofundar aqui os aspectos que fundamentam essa questão da provisão de mão de obra para outras regiões do território nacional, mas interessa-nos os fatores que universalmente favorecem a migração na sua dinâmica de expulsão e atração, posto que a mesma vai muito além de uma relação de causa e efeito, entendendo "que não é um fenômeno natural o que ocasiona a saída, mas social". ${ }^{11}$

Nesse sentido, abordaremos a seguir como os movimentos migratórios para a Amazônia nos anos 1940 envolveram os trabalhadores da zona noroeste do estado do Ceará, no esforço de guerra em produzir "mais borracha em menos tempo". Contextualizando esta conjuntura, recorremos ao que diz a historiadora Verónica Secreto:

O desenvolvimento da Segunda Guerra Mundial e acordos assinados em 1942 em Washington condicionaram a política externa do Brasil, além da ocupação e da exploração dos espaços internos. O controle japonês do abastecimento de borracha colocou aos aliados mais uma dificuldade: conseguir rapidamente um fornecedor de borracha, sobretudo para a indústria bélica. $O$ ingresso dos Estados Unidos na guerra tirou o Brasil da neutralidade, comprometendo-o a produzir "mais borracha em menos tempo". Para isso, seria necessário mobilizar grande quantidade de trabalhadores de forma rápida, o que não permitiria levar adiante o plano de colonização. A solução mais fácil e imediata era prover trabalhadores "baratos" aos seringalistas, e dessa forma se alimentou o estagnado sistema de exploração dos seringais. ${ }^{12}$

Se antes, nas levas de sertanejos que partiam para a Amazônia, o intuito era diminuir os sofrimentos da seca, preencher e colonizar os vazios demográficos, no contexto do confronto bélico iniciado em 1939, a mobilização de trabalhadores nordestinos tiraria o Brasil da neutralidade política e colocaria o Ceará novamente como estado provedor de trabalhadores para os seringais do norte, embalados por sentimentos patrióticos e iludidos com a segurança contratual oferecida aos mesmos e as suas famílias.

Ilustrativo desse momento mobilizador de braços para o esforço de guerra nos seringais nortistas, mas, por outro lado, sem esquecer os horrores do primeiro ciclo de migração para a Amazônia em 1877, são as lembranças do diálogo que o sr. Gomes, nascido em Camocim, travou com sua mãe quando anunciou para ela sua decisão de viajar:

Aí, me alistei. Cheguei em casa e contei pra minha mamãe. Ela ficou aperreada comigo: "Meu filho, tu é doido? Tu endoideceu? Perdeu teu juízo? No outro tempo quem ia para o Amazonas desejava ser uma pulga para vir nos cós de quem viesse pra cá!" Ela tava muito contrariada mesmo, aí eu

11 SECRETO, op. cit., 2003, p. 52-53.

12 SECRETO, Maria Verónica. Soldados da borracha. Trabalhadores entre o sertão e a Amazônia no governo Vargas. São Paulo: Fundação Perseu Abramo, 2007. p. 8. 
disse pra ela: "Mamãe, mas isso agora é diferente. É a mobilização". Mas ela num arredava o pé: "Tira isso da cabeça! Acaba com essa impressão besta. Esse nome aí... quantos e quantos num morreram. Lembra do Porfírio filho do sr. Manoel, lembra do que aconteceu ${ }^{13}$

Num contexto em que ir para a Amazônia parecia ser uma opção de "buscar oportunidades melhores, realizar um ato patriótico" revela uma escolha não totalmente passiva dos trabalhadores, embora num universo restrito de sobrevivência. Por outro lado, há de se analisar as apropriações das políticas de incentivo do governo Vargas para o esforço de guerra localizado na Região Norte do país. Como nos diz Verónica Secreto:

Acredito que o principal erro de todo o processo de recrutamento e encaminhamento dos imigrantes esteve na apropriação que os seringalistas fizeram de uma política de Estado. O fracasso, como em muitos outros casos de políticas públicas, se deve à distância enorme entre as planificações (incluindo em muitos casos os marcos legais criados especificamente) e a realidade na qual pensa-se em "mexer". Os trabalhadores enquadrados como "soldados da borracha" assinaram um contrato que previa o amparo a suas famílias e a campanha de recrutamento dos mesmos contou com um planejamento que implicava a criação de uma série de organismos estatais, como a Superintendência de Abastecimento do Vale Amazônico, o Banco de Crédito da Borracha, o próprio Serviço de Mobilização de Trabalhadores para Amazonas (Semta)... Mas não se implementaram mecanismos de fiscalização, nem se evitou que os grandes proprietários se "apropriassem" destas políticas em beneficio próprio. As coisas fracassam não só por falta de vontade política, embora este seja um elemento muito importante, mas pelas resistências da classe proprietária - motivo pelo qual até hoje continua a existir "trabalho escravo". ${ }^{14}$

Feitas essas considerações, partiremos para compreender como o processo de recrutamento e seus desdobramentos se deram na região noroeste do estado do Ceará, privilegiando os relatos de alguns soldados da borracha e das matérias do jornal Correio da Semana ${ }^{15}$ que versam sobre os aspectos legais do SEMTA, dentre outras fontes que informam sobre os pousos de Sobral e Tianguá. ${ }^{16}$

"Vou para os matos d'além": servir à Pátria, ganhar dinheiro e voltar.

A origem da minha viagem/ a esta santa terra/ é porque em quarenta e três/ O mundo estava em guerra/ Foi a causa de tudo/ Que nesta história se encerra/Eu já ia para a guerra/Já estava sorteado/Mas havendo necessidade/ Para a borracha fui tirado/ O bem da Pátria também era/ Um bom serviço prestado/ Sou filho do nordestino, natural do Ceará; vim embora para o Acre para a seringa cortar, produzir borracha, ganhar dinheiro, para a sua terra de origem um dia poder voltar/ [...] Fui seringueiro formado/Vivendo com os

13 Depoimento de sr. Gomes In: MORALES, Lúcia Arraes. Vai e vem, vira e volta: as rotas dos soldados da borracha. São Paulo: Annalumbre; Fortaleza: Secult, 2002 apud GOIS, Sarah Campelo Cruz. As linhas tortas da migração: estado e família nos deslocamentos para a Amazônia (1942-1944). 2013. Dissertação (Mestrado em História) - Programa de Pós-Graduação em História Social, Universidade Federal do Ceará, Fortaleza, 2013. p. 159.

14 SECRETO, Verónica. A escravidão nos seringais da Amazônia. Entrevista cedida ao jornalista Laécio Ricardo. Diário do Nordeste. Fortaleza, 24 jun. 2007. Disponível em: https://fpabramo.org.br/2007/07/06/a-escravidaonos-seringais-da-amazonia/. Acesso em: 23 jun. 2020.

15 Jornal católico semanal ainda em atividade, editado desde 1918 e de propriedade da Diocese de Sobral.

16 Cidades cearenses distantes de Fortaleza 231 km e 317 km, respectivamente, através da BR-222. 
índios em galhos de árvores trepado/ Comendo frutas silvestres/ Comendo anta e veado/ O seringueiro é um homem forte/ De uma coragem tamanha/ Enfrenta onça e enfrenta cobra lá no alto/ Da montanha, pensando no seu futuro/ Corta de noite no escuro, mas, coitado, nada ganha/ [...] Hoje eu não corto mais. ${ }^{17}$

Os versos acima são de uma testemunha ocular da história. Ex-soldado da borracha, Raimundo de Oliveira, cordelista, experimentou a guerra sendo enviado para os seringais do norte. Nos versos, a síntese do envolvimento dos nordestinos nos esforços de guerra: o recrutamento; a justificativa patriótica; o sonho de enricar; o cotidiano do seringal; os perigos e dificuldades enfrentados; a desilusão, enfim. A seguir, nos propomos a acompanhar esses homens através dos seus relatos, das notícias de jornais, notadamente a partir da região noroeste do estado do Ceará, como já se disse anteriormente, pouco lembrado na historiografia.

Como diz o título deste artigo, a mobilização junto aos trabalhadores para os seringais da Amazônia teve status de campanha nacional - e urgente. Para os esforços de guerra, nada mais eficaz do que a utilização de táticas e estratégias próprias de um "recrutamento". Segundo Mariete Pinheiro da Costa, essa prática começou

[...] nas cadeias públicas do Rio de Janeiro, São Paulo, Belo Horizonte e Porto Alegre, onde até dissidentes políticos foram "recrutados". O Nordeste brasileiro engajou-se na luta e desta vez não foram os criminosos nem inimigos políticos, mas os moradores das cidades que enfrentavam uma das piores seca na época, principalmente no estado do Ceará. ${ }^{18}$

A Campanha Nacional da Borracha, portanto, utilizou-se de forte aparato propagandístico visando o alistamento dos trabalhadores a cerrarem fileiras no então Exército da Borracha. Para tal mister, foi contratado Jean Pierre Chabloz, um pintor suíço com experiência nesse tipo de campanha, para descrever as vantagens que os soldados teriam partindo para a norte do país para produzir "mais borracha para a vitória". Cartazes e panfletos foram impressos e distribuídos aos milhares.

Por outro lado, os trabalhadores que viessem a se engajar nessa campanha - os chamados soldados da borracha - tinham seus destinos selados também por um contrato, cujas garantias nem sempre foram respeitadas pelos contratantes e nem fiscalizadas pelo Estado. A este competia a responsabilidade do encaminhamento dos trabalhadores aos seringais. Aos seringalistas cabiam cumprir as condições previstas no contrato. Embora essa operacionalização de recrutamento e envio de homens à Amazônia para a produção de borracha visasse evitar os abusos que ocorreram durante o primeiro ciclo de exploração, entre as últimas décadas do século XIX e a primeira do século $X X$, o abismo entre o que estava escrito nos contratos e a prática nas relações de trabalho continuava imenso. Ao fim

17 OLIVEIRA, Raimundo de. Em busca dos heróis da pátria. O Povo. Fortaleza, p. 1, 21 jul. 1998.

18 COSTA, Mariete Pinheiro da. O Parlamento e os soldados da borracha no limiar da $2^{\text {a }}$ Guerra Mundial. 2008. Monografia (Curso de Especialização em Instituições e Processos Políticos do Legislativo) - Centro de Formação, Treinamento e Aperfeiçoamento da Câmara dos Deputados (Cefor), Brasília, 2008. p. 24-25. 
e ao cabo, como diz a historiadora Verónica Secreto, "os únicos 'fiscais' foram os próprios trabalhadores e suas mulheres". ${ }^{19}$

\section{Figura 2 - Jean Pierre Chabloz (ao centro). Ao fundo, cartazes de propaganda da Campanha Nacional da Borracha.}

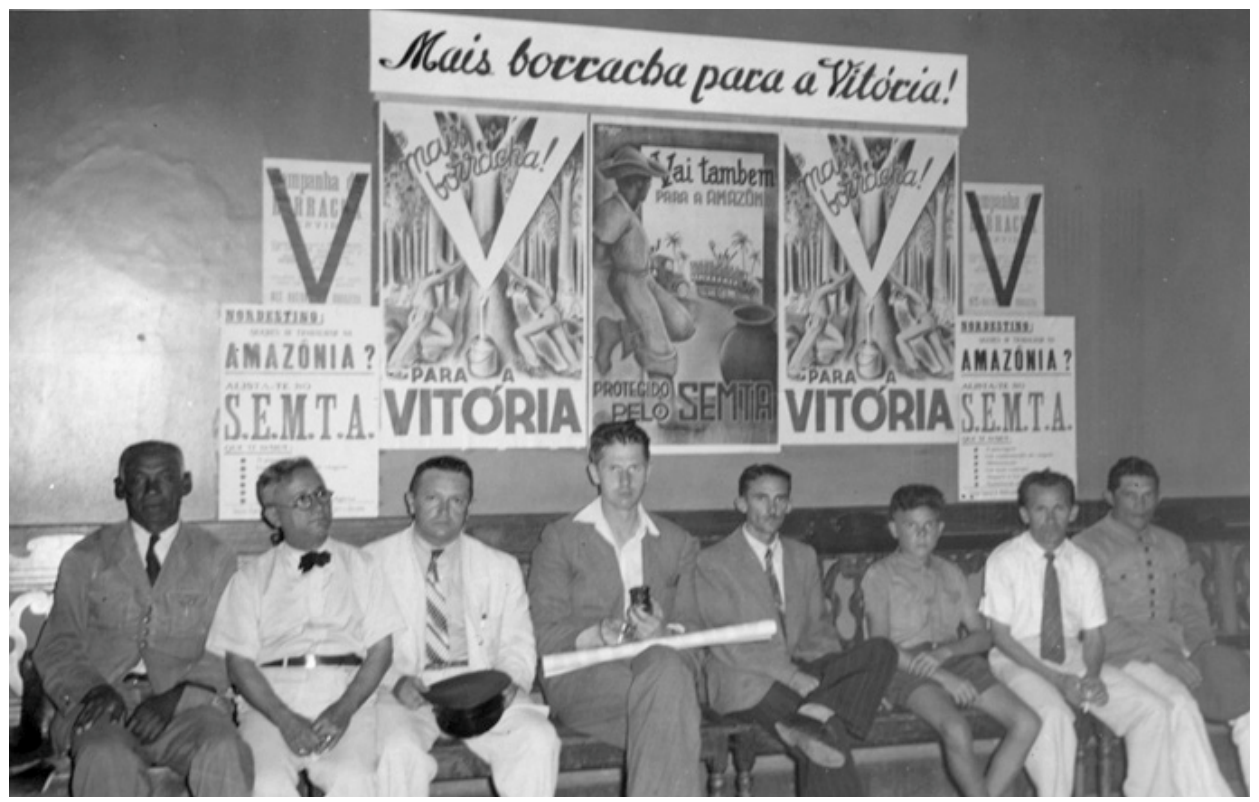

Fonte: Acervo do Museu de Arte Contemporânea da Universidade Federal do Ceará - UFC.

Voltando às condições de recrutamento de trabalhadores, a propaganda jornalística atuava como justificadora do envio de braços para os esforços de guerra. Embora o quartel general da campanha ficasse em Fortaleza, jornais do interior do estado repercutiam os discursos expressos em matérias de cunho patriótico e a "letra da lei" dos contratos, forjando uma maior transparência possível. Nesse sentido, o jornal Correio da Semana, editado em Sobral-CE, também fez parte desse esforço, trazendo matérias e notícias que positivavam o envio de trabalhadores para a Amazônia a partir do Ponto de Concentração da Cruz das Almas (Pouso do SEMTA em Sobral). Na edição de 14 de maio de 1943, o texto integral do contrato a ser assinado foi publicado. Seria extenso reproduzi-lo neste espaço. No entanto, vale ressaltar um item no contrato que deve ter pesado fortemente no aceite de milhares de trabalhadores que seguiram para o Norte - as garantias dadas às famílias dos mesmos:

Com relação ao trabalhador com dependentes diretos assistidos pelo SEMTA, serão creditados pelo SEMTA, por dia decorrido durante a vigência do contrato e nas condições anteriores, respectivamente $\operatorname{Cr} \$ 7,00$ e $\mathrm{Cr} \$$ 11,00 , e além disso, para assistência às famílias, será feito pelo SEMTA, ao fundo de assistência própria, um crédito na base de $\operatorname{Cr} \$ 2,00$ por pessoa

19 SECRETO, op. cit., 2007, p. 8-9. Para um aprofundamento desta questão do não cumprimento dos contratos e da reação das mulheres dos trabalhadores através de cartas endereçadas a seus maridos e autoridades constituídas, inclusive ao presidente Getúlio Vargas, ver: SECRETO, Verónica. Fúria epistolar: as cartas das mulheres dos soldados da borracha - uma interpretação sobre o significado da assistência às famílias. Revista Esboços, Florianópolis, v. 12, n. 14, p. 71-190, 2005. 
dependente, não superior a $\mathrm{Cr} \$ 8,00$ por trabalhador, qualquer que seja o número de dependentes, outrossim:

À família do trabalhador que optar pela assistência do SEMTA, mediante ao desconto dos vencimentos ou de quaisquer outros proventos obtidos pelo aludido trabalhador, será assegurada a continuação da assistência prevista na cláusula segunda, durante toda a vigência de trabalho no seringal; o valor dessa assistência será, para a mútua fiscalização, escriturado na base mensal na caderneta a ser emitida pelo empregador na forma das leis e regulamento em vigor;

A assistência acima referida será cessada se rescindido o contrato, ou quando a família do trabalhador se venha unir. ${ }^{20}$

A possibilidade de a família vir a se juntar ao trabalhador, como podemos observar nos itens do contrato, pode ter sido outro fator que contribuiu para que o trabalhador cearense atendesse ao chamado da Campanha Nacional da Borracha. O sonho de enriquecer ou mesmo sair dos horrores da seca para um lugar de melhores condições de vida para a família estava no horizonte de conquista desse trabalhador. No entanto, os efeitos da campanha não atiçariam a curiosidade apenas de homens deserdados pela seca. Encravado no espaço urbano, outros trabalhadores pobres ou mesmo alguns que alimentavam a perspectiva de uma vida melhor, vislumbravam naquela oportunidade uma escolha em potencial, a ponto do administrador do pouso do SEMTA de Sobral relatar para um repórter do jornal O Povo: "Você admira-se? Pois entre os trabalhadores do SEMTA encontra-se de tudo: pintores, fotógrafos, serralheiros, ferreiros, mecânicos, carpinteiros, marceneiros, profissionais de qualquer arte ou ofício que imaginar... Até sacristães!". ${ }^{21}$ Isso mostra que os caminhos da migração se dão independentes dos fatores estruturais, como assinala a historiadora Norma Sueli Semião Freitas,

[...] existem em primeiro plano as escolhas pessoais de ir e vir, ficar ou partir presentes no ato de migrar do nordestino. A partir daí, compreender esse processo migratório, o contato com outros lugares, os conflitos sociais, os deslocamentos, as mudanças e a multiplicidade de experiências advindas dele, ajuda-nos a refletir sobre a formação dos "mundos do trabalho" na sociedade moderna. ${ }^{22}$

No entanto, para ele participar dessa aventura ou dessa aposta em outras terras era preciso muito mais do que o desejo de emigrar. Esse trabalhador deveria passar por uma preparação nos pousos e campos do SEMTA para revigorar o físico, curar doenças, passar por uma seleção, de modo que os soldados da borracha deveriam chegar "ao vale amazônico em ótimas condições físicas e no melhor estado sanitário, aptos a entrar imediatamente em atividades, com boa disposição e fortaleza de ânimo". ${ }^{23}$ A preocupação em demonstrar o cuidado e zelo era tanta que se chegava ao ponto de divulgar o cardápio e as prescrições médicas a que

20 Correio da Semana, Sobral, p. 4, ano XXV, 14 mar. 1943. Fonte: Hemeroteca do NEDHIS/UVA.

21 O Povo, Fortaleza, 11 maio 1943 apud FREITAS, Norma Sueli Semião. "O meu destino é o Acre. Aquilo é uma terra santa": Amazônia, terra prometida? Grau Zero - Revista de Crítica Cultural, v. 2, n. 2, 2014, p. 108. Disponível em: https://www.revistas.uneb.br/index.php/grauzero/article/view/3269/2137.

22 Ibidem.

23 Correio da Semana, Sobral, p. 2, ano XXV, 4 jun. 1943. Fonte: Hemeroteca do NEDHIS/UVA. 
estavam sujeitos os trabalhadores internados nesses pousos e campos do SEMTA, no sentido de dar "ao Brasil o maior número possível de trabalhadores sadios e robustos, capazes de se entregarem ao trabalho de produção intensiva da borracha, sem esmorecimentos". ${ }^{24}$

Cada doente, conforme seu estado mórbido, recebe uma refeição adequada, cinco vezes ao dia, nas horas seguintes:

6 Horas - Refeição matinal: mate, café, leite, fatias passadas ou pão.

11 Horas - Almoço de acordo com a indicação médica.

15 Horas - Merenda: bananas passadas, arroz doce de leite, café e leite.

18 Horas - Jantar, de acordo com a indicação médica.

21 Horas - Ceia: mate, café, leite, pão ou fatias passadas.

A mesma atenção é dispensada à alimentação do trabalhador sadio que também recebe suas refeições a horas exatas e de padrão alimentício de alto valor, nada restando a desejar. ${ }^{25}$

Com efeito, a inauguração do campo do SEMTA em Sobral, ocorrida em 3 de maio de 1943, um mês antes da publicação da matéria acima referida, mostra o envolvimento dos segmentos sociais na mobilização de trabalhadores para o esforço de guerra na Amazônia. Desse modo, o evento recebeu as "bênçãos" dos "Josés" mais importantes da cidade, o bispo e o juiz. Enquanto D. José Tupinambá da Frota celebrou o "santo sacrifício" da missa, o juiz dr. José Saboia Albuquerque cortou a fita de inauguração. Interessante notar a construção do discurso do dr. Silva Melo na solenidade do campo do SEMTA de Sobral, cujas desculpas são pedidas antecipadamente pelo mesmo não ter nada de "suntuoso, nada de perfeito construtiva ou architetonicamente falando", ${ }^{26}$ como se isso fosse uma afronta à cidade, justificada pelo caráter excepcional de uma guerra.

Por outro lado, o conteúdo político desse discurso se alinha com os objetivos da Campanha Nacional da Borracha, destacando a conjuntura internacional da guerra e o viés patriótico necessário para justificar o empreendimento e o esforço ali inaugurados. O front da guerra distante passava a ser materializado a partir de Sobral através das instalações do "ponto de concentração de Sobral". ${ }^{27}$ Nesse sentido, a cidade, as autoridades e os trabalhadores e sociedade em geral estariam todos irmanados para lutar pela vitória do bem contra o mal. Embora um pouco extenso, um resumo do discurso publicado é necessário para que compreendamos a dimensão discursiva do mesmo.

Dentre os países livres do globo que se uniram na luta contra a opressão nipo-nazi-fascista, acha-se o nosso querido Brasil em lugar de destaque, dadas suas possibilidades naturais. E de tal vulto são nossas reservas de matérias-primas que as nações unidas já não podem prescindir d'elas para a VITÓRIA PRÓXIMA, GRANDIOSA, INFALÍVEL. Assim, nosso país, fazendo jus às expectativas de todos os povos oprimidos, e combatente contra o citado flagelo, e graças à compreensão de seus dirigentes, atendeu de pronto, entrando imediatamente nesta cruenta luta, ao abrir uma nova

26 Correio da Semana, Sobral, p. 1, ano XXV, 7 maio 1943. Fonte: Hemeroteca do NEDHIS/UVA.

27 Ibidem. 
linha de defesa e ataque concomitantemente, o "Front da Borracha". E meus senhores e senhoras essas barracas que agora ides ver são parcelas muito destacadas desse "Front". N'elas serão os soldados da borracha recebidos de braços abertos. N'elas serão inspecionados por competentes médicos e dentistas e tratados. N'elas serão alimentados, vestidos e equipados. N'elas assistirão eles aos ofícios e práticas religiosas. D'elas sairão eles, cabeça erguida, coração sereno, para se unir com seu trabalho na Amazônia, aos heróis da história contemporânea. $E$, eu vos afirmo que eles saberão se portar como aqueles imensos russos, ingleses, americanos do norte, porque eles são BRASILEIROS.

Antes de entrarmos, quero de público deixar consignado meu sincero agradecimento a Manduca Alexandre. Aos Frotas, Antônio e Pedro. A Gutemberg Monte Silva. AAntenor Ferreira Gomes. A Segismundo Rodrigues. $\mathrm{E}$ a todos quanto comigo colaboraram nesta singela construção, mas de alto valor patriótico. (sic). ${ }^{28}$

As matérias no jornal Correio da Semana prosseguiriam pelos meses de maio e junho de 1943 veiculando notícias do campo do SEMTA de Sobral, especialmente enfocando as cláusulas contratuais; as mudanças na representação e nomeações do órgão na zona norte do estado; além de revelar a trajetória desses trabalhadores rumo à Amazônia. Na matéria que traz "O texto integral do contrato de encaminhamento entre o SEMTA e os trabalhadores", diz-se que:

Depois da assinatura do contrato de encaminhamento e imediatamente antes de viajarem, os trabalhadores ainda são submetidos a um último exame de revisão pelos médicos do Serviço Especial de Saúde Pública, entidade que age coordenadamente com o SEMTA, em virtude do cuidado especial que é dedicado à saúde dos SOLDADOS DA BORRACHA, evitando assim que algum viaje tendo contraído moléstia, mesmo passageira, como distúrbios gastrointestinais ou gripe, e, do mesmo modo, desde Fortaleza, em Sobral, Teresina, São Luiz e Belém vão sendo os trabalhadores submetidos a novos exames médicos, como uma garantia de que chegarão aos pontos de locação absolutamente sadios.

Percebe-se, portanto, uma sintonia entre imprensa e Campanha da Borracha na mobilização dos nordestinos para a Amazônia no sentido de positivar essa migração, divulgando a logística da empreitada, mostrando as condições sanitárias das instalações; dos cuidados com a saúde dos trabalhadores, do amparo às famílias destes ou do mapeamento dos itinerários e os meios de transporte, como nos mostra o cartaz abaixo:

28 Correio da Semana, Sobral, p. 1, ano XXV, 7 maio 1943. Fonte: Hemeroteca do NEDHIS/UVA. 
Figura 3 - Cartaz. Meios de transporte dos trabalhadores. Pierre Chabloz.

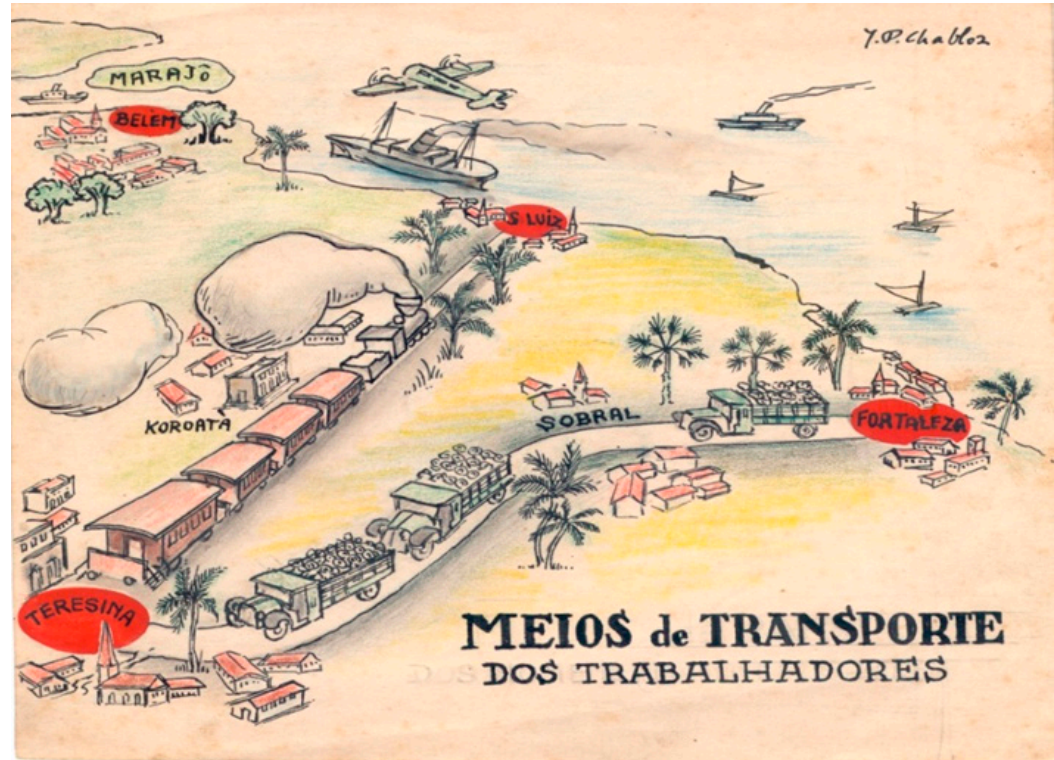

Fonte: Acervo do Museu de Arte Contemporânea da Universidade Federal do Ceará. UFC.

O itinerário rodoviário de saída dos trabalhadores cearenses para a Amazônia citado acima passou a ser bastante utilizado, em face dos perigos que o transporte marítimo passou a oferecer no contexto da guerra pela presença dos submarinos alemães no Oceano Atlântico. No trecho entre Fortaleza e Belém, acrescentou-se mais uma parada - o pouso de Tianguá -, que após a inauguração da estrada Fortaleza-Teresina, colocou a cidade na rota do SEMTA. Segundo o historiador local João Bosco Gaspar:

Chefiando o Departamento de Engenharia do SEMTA, Álvaro Vital Brazil elaborou o projeto dos pousos programados a cada 300 ou 400 quilômetros, construídos numa situação de emergência (em menos de 30 dias) e com os materiais disponíveis em cada região, utilizando a palha de babaçu, de carnaúba ou buriti (CONDURU, 2000, p. 76). O trajeto Fortaleza-Teresina (via Tianguá) era feito de caminhão pau-de-arara, dali até São Luís do Maranhão a viagem prosseguia de trem. A partir do bloqueio naval alemão em 1942, todos os "Soldados da Borracha" levados à floresta amazônica para extrair látex, passaram por Tianguá, galgando os alcantis da Ibiapaba pela sinuosa ladeira projetada por Chico da Cunha. Cerca de 60 mil nordestinos, sendo 30 mil só do Ceará, atenderam aos "apelos" da nação e, partiram levando seus sonhos de honra e riqueza para a longínqua selva Amazônica, sem ter a mínima noção dos infortúnios que os aguardavam. ${ }^{29}$

29 GASPAR, João Bosco. Tianguá... Reminiscências da história e memória dos Soldados da Borracha. Edição do Autor, 2009. p. 52. 
Figura 4 - Pouso do SEMTA em Tianguá-CE. 1943.

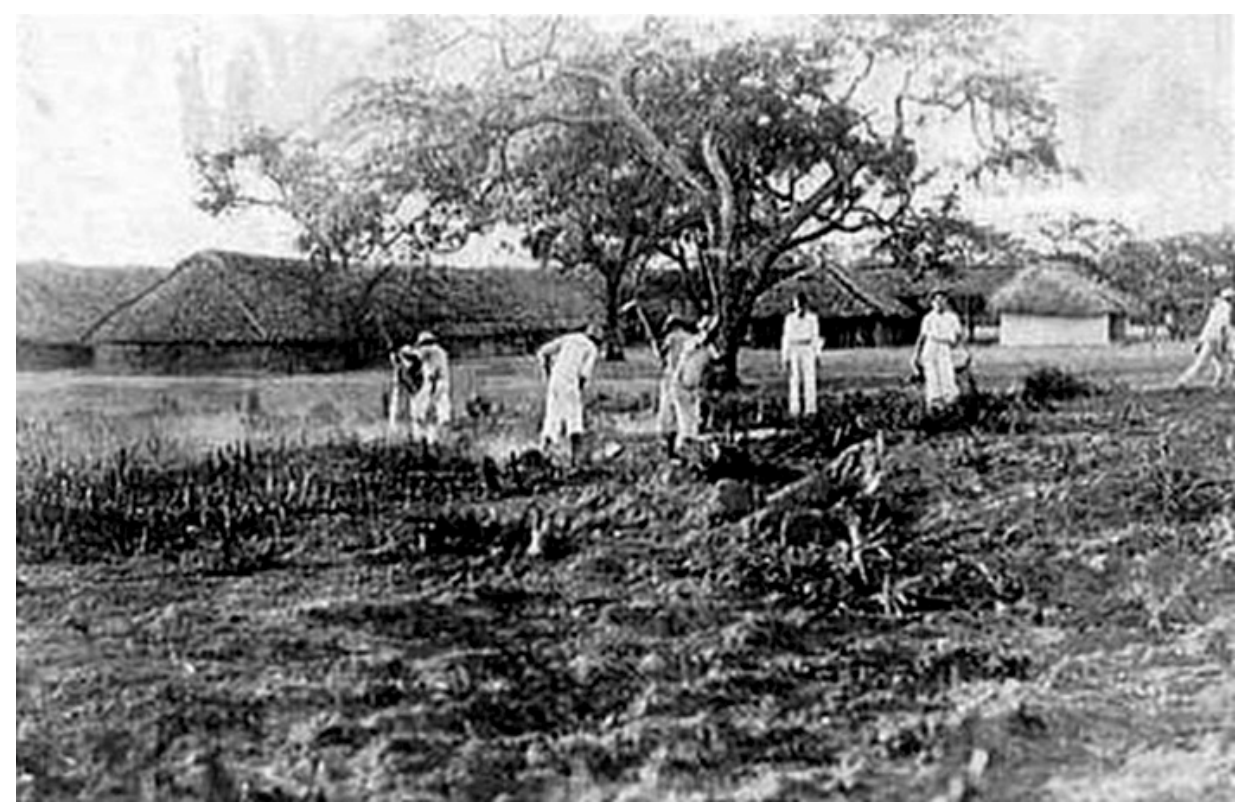

Fonte: Acervo Bosco Gaspar.

Como se pode observar pela fotografia acima, o pouso de Tianguá estava dentro das especificações quanto à utilização de matérias-primas do local com a utilização da palha de babaçu para a cobertura do teto. Esse pouso funcionou até setembro de 1943 e, por estar localizado próximo ao perímetro urbano e às margens da rodovia BR-222, possibilitou que trabalhadores de Tianguá aderissem à campanha de tentar a vida na Amazônia, com mais facilidade. A maioria dos tianguaenses foi para o estado do Amazonas trabalhar no seringal Sobral, que recebia os trabalhadores cearenses desde o primeiro ciclo da borracha no início do século XX. ${ }^{30}$ Segundo o historiador local Luciano Rodrigues da Costa, soldados da borracha oriundos de Tianguá tiveram motivações diferentes da grande maioria dos trabalhadores nordestinos para se deslocarem para o norte do país. Enquanto estes fugiam da seca de 1942, aqueles se renderam às propostas de aumento da renda familiar no trabalho nos seringais. Desse modo, Benedito Matias de Souza disse que "sua família foi convidada a ir para a Amazônia por um seringalista (dono do seringal), com uma proposta de aumento de renda através do trabalho na mata". Este parece ter sido também o caso de Raimundo Jatir Portela, que tem seu contrato de trabalho exposto na Casa da Memória de Tianguá. "Esse senhor trabalhou no Seringal Sobral, Rio Juruá, [...], no município de João Pessoa, estado do Amazonas, a partir do ano de 1943 ou 1945, sob o número de identificação 11.278". ${ }^{31}$

30 Nos dados de 1906, o seringal Sobral tinha um total de 227 pessoas, sendo 175 homens e 52 mulheres, Destes, 57 sabiam ler e 170 eram analfabetos. Relatório do Primeiro Semestre de 1906. Prefeitura do Alto Juruá. Rio de Janeiro: Imprensa Nacional, 1906.

31 COSTA, Luciano Rodrigues da. Soldados da borracha: do ideário político varguista á memória popular em Tianguá (1942-1945). 2012. (Monografia) - Curso de História, Universidade Estadual Vale do Acaraú - UVA, Sobral, 2012. p. 11-23. 
Já Justino Antônio de Sousa, embora não tenha saído do pouso de Tianguá, é natural deste município e revela como se deu o seu recrutamento, portanto, longe da opção de seus outros conterrâneos. Juntamente com dois outros irmãos seus foi alistado e "sorteado" para servir na Segunda Guerra Mundial. Quem não ia para o front era enviado para os seringais.

Quando eu fui "sorteado" para ir pra guerra, eu e dois irmãos meus, eles mandaram escolher, quem quisesse ir pra frente da frontaria, ia. E quem não quisesse, quisesse ir pro Amazonas, trabalhar na produção de borracha, (porque) que estavam perdendo a guerra pra Alemanha [...]. Eu fiquei num barracão lá, e os meus irmãos foram pra seringa. Arrumamos as estradas e tudo pra eles cortarem a seringa e eu fiquei lá, trabalhando na administração com o patrão. Uns 10 anos, eu cortei seringa. ${ }^{32}$

O testemunho fincado na oralidade, portanto, tem essa potencialidade de inserir pessoas comuns na análise histórica, apesar de todas as críticas em relação à subjetividade desse tipo de fonte. Sem querer aqui realizar um debate metodológico sobre a questão, posto que, qualquer tipo de fonte possui seus graus de subjetividade, a afirmação de Paul Thompson dá conta da justificação do uso desse tipo de fonte para este artigo: "a evidência oral pode conseguir algo mais penetrante e mais fundamental para a história. [...] transformando os 'objetos' de estudo em 'sujeitos'” ${ }^{33}$

Por outro lado, a trajetória do sr. Justino Antônio de Sousa é deveras interessante, pois revela outras possibilidades de como esses trabalhadores se adaptaram àquele ambiente inóspito dos seringais. Nesse sentido, vale salientar como esses trabalhadores em intenso anonimato, distantes de sua terra natal, conseguiram sobreviver às duríssimas condições de vida e trabalho. Vejamos o caso do sr. Justino Antônio Sousa narrado pelo documentarista:

No terceiro dia de filmagem fomos a Plácido de Castro, cidadezinha a $1 \mathrm{~h} 30$ de Rio Branco, em uma das fronteiras do Acre com a Bolívia. Nosso personagem na cidade é Justino Antônio de Souza, 82 anos, cearense de Tianguá, que se alistou como soldado da borracha durante a Segunda Guerra Mundial junto com dois irmãos. Seu Justino teve uma trajetória incomum como seringueiro e, além de extrair borracha, ajudou os patrões a amansar índios e se tornou ótimo caçador. O trabalho do seu Justino também se estendeu à saúde e ele se tornou uma espécie de enfermeiro, percorrendo os rios e matas do Acre. Em um dos momentos mais fortes de seu depoimento contou como amputou a perna de um homem picado por uma cobra. E seu Justino, acreditem, ainda canta! ${ }^{34}$

Essa adaptação, por sua vez, atravessada pelos trabalhos da memória atualiza os discursos vigentes à época da mobilização de trabalhadores para a Batalha da Borracha na rememoração da jornada que cada trabalhador experimentou. É o caso do sr. Francisco Antônio de Souza, ${ }^{35}$ conhecido como "Chico Perna", também nascido em Tianguá, que após trabalhar e viver

32 LIMA, Cesar Garcia. Soldados da borracha. Documentário. Disponível em: http://soldadosdaborracha. blogspot.com.br. Acesso em: 25 jun. 2020.

33 THOMPSON, Paul. A voz do passado. São Paulo: Paz e Terra, 1992. p. 137.

34 LIMA, op. cit. apud COSTA, op. cit., p. 21.

35 Francisco Antônio de Souza, solteiro, residente em Tianguá, nascido em 17 de dezembro de 1918 em TianguáCE. Foi para o Amazonas em 11 de junho de 1943 e recebeu o n 11.215 no Serviço de Mobilização de Trabalhadores para a Amazônia (SEMTA). 
por 50 anos no estado do Amazonas, volta para sua terra natal em $1977 .{ }^{36} \mathrm{Em}$ entrevista concedida ao historiador Luciano Rodrigues da Costa, diz:

Eu fui em 1943. Eu passei 50 anos lá [...]. A gente vai se misturar com índio brabo, índio manso, cobra, jacaré, onça, e toda qualidade de fera. Então... [...] passei uns doze anos, dentro da mata, trabalhando. Nós fizemos um contrato com o governo federal, que era o Getúlio Vargas, pra ir trabalhar no Amazonas na extração da borracha, pra ajudar a vencer a guerra, naquele tempo tava em guerra, [...] e o país tava em guerra e ele não sabia mais o que fizesse. ${ }^{37}$

Continuando na recuperação das memórias de ex-combatentes do chamado Exército da Borracha, alguns aparecem como personagens de matérias em jornais e blogs da região noroeste do estado do Ceará, quase sempre evidenciando um conteúdo heroico por suas façanhas nos seringais, por suas trajetórias esquecidas pelos governos ou suas provas de patriotismo para com a nação. O sr. Félix Rodrigues Lopes é um deles, que em 2013 completou 100 anos de idade. ${ }^{38} \mathrm{Na}$ homenagem prestada pelo blogueiro, não basta o reconhecimento do sr. Félix como "uma personagem histórica viva no município de Forquilha". É necessário relacionar sua participação naquele evento com "um dos maiores conflitos armados do século XX, a Segunda Guerra Mundial, servindo à Pátria na função de Soldado da Borracha aos 30 anos de idade na região da Amazônia". Como podemos perceber, não somente os historiadores são instituidores de relações de sentido tendo como base as trajetórias de vida das pessoas. No processo de construção deste discurso, muitas vezes as condições de trabalho a que esses trabalhadores estavam relegados são esquecidas. Nesse caso, o que importa mais é ter um sujeito na comunidade que incorpore uma relação de identidade com o município para que este figure na história do país. O fato de ter sobrevivido e fazer 100 anos é o bastante:

A cidade de Forquilha tem na pessoa de seu Félix Rodrigues um olhar especial, pois, ele faz história e sua atitude de ter saído de sua terra para ir a um lugar desconhecido em tempos de guerra (e sua maior proeza ainda é de estar vivo contando sua história) faz dele um arquivo vivo dos fatos históricos. ${ }^{39}$

Ter escapado da malária e "voltado ao solo forquilhense" torna, portanto, o sr. Félix um ícone que merece um lugar "num futuro próximo, quem sabe nos meios pedagógicos de nosso município", profetiza o blogueiro de Forquilha, já evidenciando no registro do seu texto "algo útil para servir de estudos para a posteridade contribuindo para uma reflexão do homem em

36 Naquele ano, 1977, o sr. Francisco Antônio de Souza faz um Auto de Declaração no cartório local como soldado da borracha visando adquirir seus direitos junto ao governo federal. Fonte: COSTA, op. cit., p. 23. No dia 28 de dezembro de 1989 o presidente José Sarney sancionou a Lei № 7.986, publicada no Diário Oficial da União do dia seguinte, concedendo aos seringueiros e seus descendentes, que trabalharam durante a Segunda Guerra Mundial nos seringais da Região Amazônica, o pagamento de pensão vitalícia correspondente a dois salários mínimos vigentes no país. Fonte: Gazeta do Acre. Soldados têm lei em seu favor. Rio Branco, 22 jun. 1988.

37 Apud COSTA, op. cit., p. 23.

38 Félix Rodrigues Lopes, nascido no dia 21 de junho de 1913, na localidade de Várzea da Cobra em ForquilhaCE, filho de Francisco Rodrigues Lopes e Joaquina Sousa Lopes. Fonte: CAVALCANTE, Célio. Centenário de vida do ex-combatente Félix Rodrigues Lopes. Disponível em: http://forquilhaontemhojeesempre.blogspot. com/2013/06/centenario-de-vida-do-ex-combatente.html. Acesso em: 2 jul. 2019. Ibidem. 
seu tempo". 40 Da mesma forma, outros exemplos podem ser citados, como o do sr. Edson Machado Portela, ${ }^{41}$ natural de Crateús-CE, que em 2016 completou 101 anos de idade em Rio Branco, capital do Acre. Na oportunidade em que a matéria foi realizada, já tinha perdido parte da memória, e quem recorda os anos de dificuldades e desbravamento da selva amazônica são seus familiares. Diz sua neta Márcia Cristina Portela de Mesquita:

Durante esses meses que passaram em viagem, meu avô e os homens recebiam treinamento de guerra e sofriam com as moléstias amazônicas. Muitos deles ficaram pelo caminho. [...] Meu avô e os demais soldados tiveram aqui um trabalho desafiador de reabrir os seringais de seringa nativa e produzir o látex para abastecer os países aliados na guerra mundial. [...] Meu avô é um homem, que apesar da pouca educação, criou todos os filhos voltados para o trabalho. Foi temido na juventude e respeitado pela seriedade e honestidade dispensada ao próximo. Por isso nossa homenagem a ele pelos 101 anos de vida. ${ }^{42}$

O sr. Edson Machado Portela foi um dos milhares de cearenses que acabaram fincando suas raízes no norte do país. Desse modo, sua trajetória de vida é também compartilhada com a história de outro estado. Como diz a articulista ao final da matéria: "é parte da memória, não só da família, mas da história do Acre". ${ }^{43}$ Ainda de Crateús, os relatos memorialísticos sugerem que dezenas de pessoas desse município foram alistadas para servir na Segunda Guerra Mundial e participaram da Batalha da Borracha, conforme o texto "Ombora Pessoal! Bora cuidar! Bora se virar!", hospedado na página da Academia de Letras de Crateús. ${ }^{44} \mathrm{Em}$ tons épicos, a narrativa procura ligar os espaços dessa história, iniciando com a descrição dos rigores da seca do sertão crateuense ao centro de decisões governamentais na capital da República e o local de trabalho e suas condições no seio dos seringais. Os trechos da citação abaixo contemplam esses três momentos:

Um vento quente que incomoda, até a sombra de um desbotado juazeiro bafeja nos rostos fantasmagóricos de seres semivivos que, de enxada na mão, ciscam um duro chão e remoem a desmedida fome com o último pão de macambira que havia no sertão.

[...] Há léguas e léguas dali, na Cidade Maravilhosa, Capital do País, em plena $2^{\mathrm{a}}$ Guerra Mundial, um Getúlio Vargas que comandava ditatorialmente um sistema de governo bem próximo a um nazi-fascismo, mas com o rabo preso aos americanos por uma dívida estratosférica, recebia, hesitante, as ordens do presidente americano Franklin Delano Roosevelt: - Vamos precisar de borracha para vencer a guerra! Já que os japoneses tomaram a floresta de seringais, na Malásia, plantada pelos ingleses com as sementes que levam daqui. A Amazônia será a nossa salvação!

40 Ibidem.

41 Edson Machado Portela saiu de Fortaleza em 22 de agosto de 1944 como soldado da borracha sob o $\mathrm{n}^{\circ} 29.761$. Trabalhou por mais de 40 anos nos seringais. Após completar 65 anos de idade, teve acesso a uma aposentadoria de "soldado da borracha". A indenização foi recebida recentemente, no valor de R\$ 25 mil. Fonte: FABRÍCIA, Celis. Ex-soldado da borracha comemora 101 anos nesta sexta-feira. Disponível em: https://agencia.ac.gov. br/ex-soldado-da-borracha-comemora-101-anos-nesta-sexta-feira/. Acesso em: 4 jul. 2019. Ibidem.

43 Ibidem

44 O título do texto é uma referência a um dos capítulos de mesmo nome do livro de MORALES, op. cit., 2002. 
[...] Mal o dia amanhece já caminham por uma esteita alameda, deixando tigelas coladas nos troncos das seringueiras, bebendo o precioso suco leitoso. lam descalços sobre estivas de grossos troncos e finos palmitos, se escorregassem na lama levavam uma alta descarga voltaica dos cilíndricos puraquês. No fim da trilha, ao meio-dia, almoçavam o que tinham para comer, pois logo voltariam recolhendo as vasilhas lotadas de látex, se os perigosos e traquinas silvícolas não as tivessem derramado. A noite ficava reservada para a defumação, onde eram feitas as enormes bolas de borracha, as pélas. De segunda a segunda, nesta imutável rotina, induzia as boas lembranças ou a torturosas saudades, da vida de um sertanejo, cada vez mais distante do longínquo Ceará. ${ }^{45}$

\section{Algumas considerações}

"Aos 80 ANOs, arrastando-se para 90, eles estão morrendo de doenças e achaques da velhice. Todos, porém, se queixam de um mal maior. Estão morrendo asfixiados pela mágoa e pela dor do descaso a que foram relegados no passado até os dias atuais". ${ }^{46}$ Mais do que um lamento, uma constatação. De 2015, ano em que o jornalista Silvio Martinello escreveu a frase acima, para cá, nada mudou para os trabalhadores que foram "estropiados, maltratados e triturados" na Amazônia.

De tempos em tempos a saga dos soldados da borracha ocupa espaços na mídia, principalmente quando alguma data alusiva se arredonda ou se pauta a eterna luta por direitos conquistados e não honrados pelo governo.

Por outro lado, a academia vez por outra também se debruça sobre a questão através de trabalhos acadêmicos de graduação, mestrado e doutorado. Neste artigo, minimamente procurou-se mapear alguns desses soldados ligados à região noroeste do estado do Ceará. No entanto, a grande maioria desses trabalhadores continua e continuará no anonimato, perdidos nos desvãos da memória e da história. Daqui a pouco não teremos mais como entrevistá-los face ao avanço da idade.

No entanto, pensamos que muito ainda pode ser explorado a partir da documentação produzida no período, que possibilitará entrever as várias dimensões desses sujeitos sociais que fizeram suas escolhas, dentro daquilo que a historiadora Verónica Secreto pontua: "Escolhas dentro de um número limitado de opções, mas escolhas. Ir para o Amazonas, para muitos deles, significou seguir uma saga familiar, buscar oportunidades melhores, realizar um ato patriótico", ${ }^{47}$ fazendo com que não os tomemos sempre como vítimas.

45 CANDIDO, Raimundo. Ombora Pessoal! Bora cuidar! Bora se virar! Tributo aos heróis crateuenses que combateram na Guerra da Borracha. Disponível em: http://academiadeletrasdecrateus.blogspot.com. br/2012 0715 archive.html. Acesso em 10 dez. 2019.

46 MARTINELLO, Silvio. Eles estão morrendo. In: ARAÚJO, Ariadne; NEVES, Marcos Vinicius. Soldados da borracha: heróis esquecidos. $1^{a}$ ed. São Paulo: Escrituras Editora; Fortaleza: Irê Brasil Produções Artísticas, 2015. p. 11.

47 SECRETO, Verónica. A escravidão nos seringais da Amazônia. Entrevista cedida ao jornalista Laécio Ricardo. Diário do Nordeste. Fortaleza, 24 jun. 2007. Disponível em: https://fpabramo.org.br/2007/07/06/aescravidao-nos-seringais-da-amazonia/. Acesso em: 23 jun. 2020 
Nosso esforço neste momento foi apenas procurar evidenciar essa história no espaço regional do noroeste cearense, ainda pouco explorado na historiografia sobre o tema.

Nesse sentido, para o objetivo deste artigo, esperamos que, mesmo minimamente, através desses testemunhos se possa imaginar a contribuição que esses trabalhadores deram para o esforço de guerra referenciado. Foram turmas de milhares de homens que se deslocaram de suas comunidades; que trabalharam anos a fio longe de suas famílias; enfrentaram as piores condições de vida e trabalho; que foram enganados pelo governo e pelos patrões; que refizeram suas vidas em múltiplas estratégias de negociação e sobrevivência; que não enricaram e nem voltaram mais para o seu chão; que morreram longe da terra natal.

Mas, também voltaram para contar as histórias que viveram...

Recebido em 04/07/2020

Aprovado em 09/02/2021 